\author{
Нгуен Фам Бао Чам \\ Студентка 4 курса, факультет Экономики торговли и товароведения \\ Российский экономический университет имени Г.В.Плеханова, \\ Российская Федерация, г. Москва, 117997, Стремянный пер., 36 \\ E-mail: baotram221196@gmail.com
}

\title{
ИДЕНТИФИКАЦИЯ ТОВАРОВ В ЦИФРОВОЙ СРЕДЕ
}

\begin{abstract}
Аннотация. В статье рассматривается важность идентификации и прослеживаемости продукции в современных условиях с учетом цифровизации экономики. Статья выполнена под научным руководством к.э.н., доцента Ильяшенко С. Б., кафедра торговой политики РЭУ им. Г. В. Плеханова.

Ключевые слова: инновации, идентификация, е-commerce, цифровая среда
\end{abstract}

Введение. Цифровая экономика как синергия основных факторов производства и интеллектуального капитала, открывает новые перспективные возможности для ведения предпринимательской деятельности. Конфигурация глобальных рынков претерпевает значительные изменения, с одной стороны, под действием цифровизации, и, с другой стороны, генерацией кардинально новых потребностей у потребителей $[1,2]$. Поскольку торговые организации являются конечным звеном в системе распределения, представляется важным применение инновационных подходов, которые обеспечивают их стабильное функционирование $[3,4]$.

Идентификация товаров - это одна из разновидностей маркировки, которая включает такие функции, как отслеживание товара, защита бренда, а также различного рода информационные этикетки. В условиях быстро меняющейся бизнес-среды и постоянных угроз со стороны противоправных действий и контрафактной продукции идентификационная маркировка продукта имеет большое значение. Ее также можно отнести к числу средств, применяемых торговыми организациями для обеспечения положительной динамики развития [5]. Особенно учитывая, что обман потребителя, связанный с введением в оборот товаров - подделок, с изменением вида, качества или свойств товаров, или имеющих скрытые свойства и качества, информация о которых является заведомо неполной или недостаточной [6], увеличивается с возрастающей скоростью.

Основная часть. С расширением глобальной торговли, компьютеризации и коммуникаций описание товаров и услуг на понятном языке должны быть заменены системами идентификации и отслеживания, которые могут использоваться во всех секторах торговли и промышленности во всем мире.
Прослеживаемость товара - это процесс ведения учета всех материалов и деталей от покупки до готовой продукции, где уникальный номер идентифицирует деталь, партию или готовую продукцию. При этом прослеживаемость дает возможность идентифицировать и отслеживать продукт или компонент до его происхождения. Отправной точкой может быть конкретная партия или партия, производственная линия и временные рамки, поле или поставщик [7]. Отслеживание продукта очень важно для надежности. Если после использования в уже проданном продукте определенная партия критического компонента окажется дефектной, прослеживаемость позволяет идентифицировать единицы для отзыва. Некоторые продукты (например, авиационные компоненты, свежие продукты, мясо) требуют полной прослеживаемости. Вот некоторые из преимуществ и решений, предоставляемых для идентификации и прослеживаемости продукта:

1) Процедуры идентификации и отслеживания продукта на всех этапах производства, доставки и установки.

2) Возможность получения достоверной информации и том, какие компоненты входят в продукт, их технические характеристики, их статус и т. д.

3) Повышение эффективности проведения основных видов товарной экспертизы, к которой относятся санитарно-гигиеническая, карантинная, ветеринарная и экологическая [8].

Примером может выступать автоматизированная информационная система «Меркурий», которая предназначена для электронной сертификации и обеспечения прослеживаемости товаров, которые в силу Приложения к приказу Минсельхоза России от 18 декабря 2015 года №648 «Об утверждении перечня подконтрольных товаров, подлежащих со- 
провождению ветеринарными сопроводительными документами» (с изменениями от 27.06.2018 года) попадают под государственный ветеринарный надзор $[9,10]$.

С 1 июля 2018 года к ГИС «Меркурий» обязаны подключиться такие категории хозяйствующих субъектов, как молочные заводы, мясокомбинаты и птицефабрики, производители морепродуктов, дистрибьюторы и торговые сети.

Несомненным преимуществом перехода от традиционных бумажных к электронным документам является сокращение расходов предприятия, исключение ручного ввода данных в ГИС и, как следствие, снижение вероятности ошибки при заполнении форм вручную, ускорение получения электронных сертификатов. Идентификация и прослеживаемость товара выполняет следующие функции:

1. Пользователь может однозначно идентифицировать товар с точки зрения аутентичности, номера производственного заказа, номера технологического заказа, номера партии и номера контрольного заказа на всех этапах производства. Он также связывает каждый элемент компонента, будь то материал, процесс, измерительный прибор или персонал, с любыми связанными действиями для конечного результата или прослеживаемости.

2. Уникальная идентификация продукта.

3. Связь с применимыми чертежами, спецификациями, изменениями и записями качества [11].

4. Прослеживаемость к персоналу, оценка качества его работы.

5. Прослеживаемость к оборудованию, измерительным приборам, инструментам, которые используются в процессе производства.

Одна из разновидностей идентификации штриховое кодирование. Система нумерации штрих-кодов обеспечивает глобальную уникальность и способствует разрешению проблем путаницы, дублирования и неправильного толкования, поскольку все ее пользователи следуют одним и тем же правилам кодирования. Также отметим, что в России с 2017 года идет постепенный переход к введению единой обязательной маркировки на все товары. Распоряжение от 28.04.2018 №791-р «Об утверждении модели функционирования системы маркировки товаров средствами идентификации в Российской Федерации» предусматривает трех- ступенчатый переход к маркировке. Первый этап присвоение товарам уникальных кодов, т.е. проведение сплошной идентификации каждой товарной единицы. Второй этап предусматривает создание информационной системы маркировки, в которой будет храниться вся информация, генерируемая всеми участниками системы маркировки в процессе жизненного цикла товара. Далее предполагается создание Единого каталога товаров.

Для отслеживания продукта требуются идентификационные этикетки, обычно содержащие идентификационный номер или штрих-код. Идентификационные метки могут использоваться для идентификации партий или отдельных предметов $[11,12]$. Для этого доступно множество технологий маркировки. Рассмотрим некоторые.

Виниловые или полиэфирные этикетки иногда используются для идентификации продуктов и отлично подходят для отслеживания продуктов, где безопасность не является главной проблемой. Разнообразные этикетки для разнообразного применения могут быть легко изготовлены с использованием промышленного принтера этикеток [13]. Однако основной их недостаток заключается в том, что они могут быть относительно легко удалены или подделаны. Более прогрессивной технологией является нанесение ультрафиолетового знака, который виден только в ультрафиолетовом свете, что затрудняет их копирование. Также применяются и переменные информационные метки. В этом случае информация о товаре на этикетке позволяет провести идентификацию товара, а также получить дополнительную информацию (например, такую как дату изготовления, срок годности, идентификационные коды партии, место производства или номера партий и т.д.). Эта информация может быть в виде текста и чисел, штрих-кодов.

Заключение. Подводя итоги проведенного исследования отметим, что в современных условиях роль идентификации товаров не сводится только к штриховому кодированию. Идентификация способствует повышению конкурентоспособности торговой организации, т.к. потребитель испытывает больше доверия к тому товару, который он может однозначно распознать и самостоятельно выявить фальсификат или контрафакт, не прибегая к дорогостоящей экспертизе.

\section{Список использованных источников}

1. Захарова И. И., Толстова Е. Г. Информационная идентификация мороженого как определяющий фактор возможности его использования на предприятиях общественного питания // Научно-методический электронный журнал «Концепт». - 2018. - № 4 (апрель). - С. 189-196.

2. Иванов Г .Г., Зверева А. О. Развитие торговых организаций в современной экономике: Монография- Москва, Изд.-торг. «Дашков и К», 2018. - 160 с. 
3. Юдникова Е. С., Ильяшенко С. Б. Вектор развития инновационного потенциала в торговле на основе внедрения «online-to-offline» коммерции // Российское предпринимательство. 2018. Т. 19. № 11. С. 3313-3322.

4. Сычева Е.И., Самойлова В.В. К вопросу о наличии признаков предпринимательской деятельности у патронатной семьи как российского варианта «фостерной» семьи // Семейное и жилищное право. 2017. № 1. С. 21-24.

5. Дорофеев М.Л., Косов М.Е. Роль и перспективы внедрения криптовалют в современную мировую финансовую систему // Финансы и кредит. 2019. Т. 25. № 2 (782). С. 392-408.

6. Турищева Т.Б. Роль и место внутреннего контроля в системе управления автономных учреждений // Аудитор. 2018. T. 4. № 2. С. 11-15.

7. Самченко Я. Р., Латыпова О. В., Тепина Ю. В. Информационная идентификация строительных товаров // Научно-методический электронный журнал «Концепт». - 2017. - Т. 24. - С. 105-108.

8. Чайковская Л.А., Галайда А.М. Проблемы гармонизации бухгалтерского и налогового учета основных средств // Экономика и управление: проблемы, решения. 2017. Т. 2. № 8. С. 36-44.

9. Зверева А.О., Иванов Г.Г. Механизмы развития торговых организаций в неблагоприятных экономических условиях. Монография / А. О. Зверева, Г. Г. Иванов. Москва, 2010.

10. Бухарева Л.В., Городецкая М.И., Дмитриева И.М. и др. Бухгалтерский финансовый учет: учебник. -2-е изд. М.: Юрайт, 2017. -(Бакалавр. Академический курс)

11. Akhmadeev R.G., Kosov M.E., Bykanova O.A., Frumina S.V., Melnichuk M.V. Taxation of end consumption: effect on country economies and its characteristics//American Journal of Applied Sciences. 2017. T. 14. № 3. C. $381-391$

12. Зверева А. О., Ильяшенко С. Б. Инновационные решения в торговле в контексте глобальных экономических процессов // Российское предпринимательство. 2018. Т. 19. № 3. С. 609-618.

13. Мастеров А.И. Применение методов математического программирования в управленческом анализе ассортиментной политики организации // Актуальные проблемы социально-экономического развития России. - 2010. №4. - С. 53-56.

\author{
Nguyen Pham Bao Tram \\ 4th year student of the faculty of Economics of trade and commodity \\ Plekhanov Russian University of Economics \\ Russian Federation, 117997, Moscow, Stremyanny lane, 36 \\ Email: baotram221196@gmail.com
}

\title{
PRODUCT IDENTIFICATION IN THE DIGITAL ENVIRONMENT
}

Summary. The paper discusses the importance of identification and traceability of products in a modern economy. Strong and weak analysis of identification methods has been used and the lead to innovations in labels' industry.

Keywords: innovation, identification, traceability, economic, e-commerce, digital environment, labels 